\title{
PENDAMPINGAN REMAJA DI KABUPATEN KUNINGAN JAWA BARAT DALAM PENGGUNAAN MEDIA SOSIAL INSTAGRAM SEBAGAI PELESTARIAN BUDAYA
}

\author{
Dianingtyas M. Putri ${ }^{1}$, Eli Jamilah Mihardja ${ }^{2}$, Prima Mulyasari Agustini ${ }^{3}$ \\ Program Studi Imu Komunikasi, Universitas Bakrie, Jakarta, 12960, Indonesia \\ E-mail: ${ }^{1}$ dianingtyas.putri@bakrie.ac.id*, ${ }^{2}$ eli.mihardja@bakrie.ac.id, ${ }^{3}$ prima.agustini@bakrie.ac.id \\ DOI: https://doi.org/10.36782/ijsr.v1i02.13
}

\begin{abstract}
Abstrak
Memasuki era 4.0 yang dikenal sebagai era disrupsi, dibutuhkan inovasi, problem solving, dan kreativitas untuk menghadapinya, sehingga mengharuskan beragam aspek untuk maju dan dapat mengikuti perkembangan kemajuan teknologi di beragam aspek, salah satunya aspek pariwisata. Kurangnya mengenalkan potensi kearifan lokal budaya yang dimiliki melalui promosi dengan penggunaan media sosial khususnya Instagram menjadi sumbatan mengapa aspek pariwisata ini perlu digalakan. Agar efektif, maka perlu diberikan pembekalan mengenai optimalisasi penggunaan media sosial khususnya Instagram untuk melakukan promosi pariwisata dan mengenalkan potensi kearifan lokal yang dimiliki oleh Kabupaten Garut, seperti seni Wayang Golek, Surak Ibra, dan sebagainya yang dikenalkan kembali melalui Heman Ka Budak merupakan kesenian Sunda yang diadakan helaran mingguan kebudayaan dan kesenian Kuningan dengan mengangkat kesenian asli yang berkolaborasi dengan seniman muda Kuningan. Pengabdian ini bertujuan untuk meningkatkan pemahaman masyarakat khususnya remaja milenial Generasi Z tentang upaya pelestarian budaya lokal melalui media sosial Instagram, dan mempromosikan budaya lokal di Kabupaten Kuningan Jawa Barat. Metode dalam pelaksanaan program pengabdian masyarakat ini meliputi observasi awal daerah kegiatan, pemetaan masalah, pelaksanaan kegiatan dengan mengikutsertakan mahasiswa, serta pendampingan berupa pelatihan penggunaan media sosial Instagram sebagai pelestarian budaya. Hasil kegiatan pengabdian masyarakat menunjukan bahwa setelah mengikuti pelatihan meningkatkan kesadaran peserta dalam penggunaan media sosial Instagram sebagai pelestarian budaya, serta peserta mempunyai keterampilan dalam membuat promosi budaya yang menarik dan efektif melalui Instagram.
\end{abstract}

Kata Kunci: pelestarian, budaya, kesadaran, Instagram, Kuningan

\begin{abstract}
Entering the 4.0 era, known as the era of disruption, innovation, problem-solving, and creativity are needed to deal with it, thus requiring various aspects to advance and be able to keep abreast of technological advances in various aspects, one of which is tourism. The lack of introducing the potential of local cultural wisdom possessed through promotion with the use of social media, especially Instagram, is a barrier to why this aspect of tourism needs to be promoted. To be effective, it is necessary to provide human capital training on optimizing the use of social media, especially Instagram to promote tourism and introduce the potential of local wisdom owned by Garut Regency, such as Wayang Golek, Surak Ibra, etc. which are reintroduced through Heman Ka Budak are Sundanese
\end{abstract}


art which is held a weekly culture and Kuningan art exhibition by raising the original art in collaboration with young Kuningan artists. This service aims to increase public understanding, especially Generation Z millennial youth about efforts to preserve local culture through social media Instagram, and promoting local culture in Kuningan, West Java Regency. The methods in implementing this community service program include initial observation of the activity area, problem mapping, implementing the activity by involving students, community assistance in the form of training to use Instagram social media as a cultural preservation. The results of community service activities show that after participating in training increases awareness of participants in using Instagram social media as cultural preservation, and participants have the skills in making attractive and effective cultural promotions through Instagram.

Keywords: preservation, culture, awareness, Instagram, Kuningan

\section{Latar Belakang}

Memasuki era revolusi 4.0, mengharuskan beragam aspek seperti aspek ekonomi, pendidikan, industri, dan pariwisata untuk mengikuti kemajuan teknologi berbasis digital. Melalui acara Musyawarah Nasional (Munas) yang disampaikan oleh Presiden Republik Indonesia Joko Widodo, mengenai harapan Bangsa Indonesia mampu bersaing dengan negara lain dalam berbagai hal, tentu pesan ini memberikan maksud serta tujuan dan kesadaran bahwa bagaimana cara kita untuk dapat menggunakan media internet serta optimalisasi pengunaannya bukan untuk diri sendiri, sebagai pemenuhan pribadi, namun bisa memberikan kontribusi pada hal yang lebih besar cakupannya. Era revolusi 4.0 dikenal sebagai era disrupsi, dimana beragam sektor hukum, ekonomi, politik, dan sebagainya sedang melakukan peningkatan. Bagaimana dengan kebudayaan?

Kebudayaan seringkali dianggap sebagai sesuatu yang tidak menarik karena memiliki sifat tradisional, kuno, dan tidak dibumbui dengan gaya kekinian dari pergaulan anak muda zaman sekarang. Arus kemajuan era globalisasi dan modernitas di masyarakat menimbulkan kesan yang saling berlawanan antara budaya dengan kemajuan teknologi.

Teknologi menjadi sebuah hasil inovasi perkembangan kecerdasan manusia yang harus dianggap secara baik, jika tidak akan menimbulkan permasalahan sosial yang akan merambah pada jati diri dan identitas bangsa Indonesia yang berbudaya. Teknologi menjadi sebuah hasil inovasi perkembangan kecerdasan manusia yang harus dtanggapi secara baik, jika tidak akan menimbulkan permasalahan sosial yang akan merambah pada jati diri dan identitas bangsa Indonesia yang berbudaya.

Dilansir dari media online Bisnis.com dengan judul wacananya "Generasi Milenial Perlu Jaga Kearifan Lokal" menyampaikan bahwa arus globalisasi dan informasi begitu cepat mempengaruhi cara pandang, budaya, dan gaya hidup di kalangan generasi milenial. Sehingga terdapat implikasi secara sosial adanya kecenderungan remaja memiliki karakter ingin serba instan, karena asyik berkutat dengan smartphone yang menyediakan banyak hal secara mudah dan cepat.

Agus Gumiwang Kartasasmita selaku Menteri Sosial Republik Indonesia pun menambahkan bahwa kearifan lokal di Indonesia merupakan salah satu pilar yang penting bagi terciptanya harmonisasi hubungan yang baik antar masyarakat, termasuk dalam pemanfaatan sumber daya alamnya agar tidak menimbulkan konflik secara sosial. Dengan kata lain, adanya teknologi yang marak saat ini ternyata sudah menggeser aktivitas atau kegiatan 
masyarakat khususnya remaja yang awalnya dilakukan di dunia nyata beralih ke dunia maya.

Dr. Tri Kuntoro Priyambodo. M.Sc. menjelaskan derasnya arus budaya asing yang masuk telah mengakibatkan perilaku dan nilai-nilai dalam kehidupan dan pergaulan masyarakat tidak lagi berpegang pada nilai-nilai dan akar budaya Indonesia. Tri Kuntoro menyampaikan dalam Diskusi Selasa Pagi dengan tema "Kebudayaan, Nasionalisme, dan Pancasila dalam Tembang, Gending, dan Geguritan" di Pusat Kebudayaan Koesnadi Hardjasoemantri (PKKH) Universitas Gajah mada (UGM) di Yogyakarta.

Hal ini dimaksudkan karena belakangan ini masyarakat kita lebih mengutamakan untuk mengikuti arus budaya global dan melupakan nilai-nilai budaya asal yang berasal dari nenek moyang kita dulu. Faktor utamanya adalah kurang mengenalkan budaya lokal pada generasi penerus dengan memanfaatkan media digital secara optimal. Tidak hanya itu di Kabupaten Kuningan Jawa Barat memiliki banyak seni budaya lokal namun akibat terkikisnya budaya asal dengan datangnya budaya baru, dan tidak dipelihara oleh generasi penerusnya maka seni budaya yang memiliki potensi punah. Kepala Balai Pelestarian Nilai Budaya (BPNB) Bandung Toto Sucipto di Bandung menyampaikan terdapat sekitar 39 seni tradisional yang pernah hidup di Jawa Barat kini punah dan tidak dipentaskan kembali, dalam nasional.kompas.com dengan judul "39 Kesenian Jabar Punah". Toto Sucipto menambahkan "Jika tidak pernah dipentaskan dan tak ada regenerasi, seni tradisional tersebut bakal punah". Beberapa kesenian tidak pernah ditampilkan pada generasi sekarang, namun tercatat dalam sejumlah naskah lama adalah Karawitan Elet, Empet, Mamanukan, dan Sarawelet.

Promosi kebudayaan yang selama ini terbatas pada penggunaan media-media yang konvensional, harus segera diubah. Keberadaan teknologi informasi (IT) dan perkembangannya harus ditanggapi dengan cepat, dengan memunculkan terobosanterobosan baru dalam promosi kebudayaan. Penggunaan media internet menjadi salah satu solusi yang dapat digunakan, disamping media-media konvensional dan kegiatan pertukaran budaya. Selain itu, kurangnya pemahaman dan inovasi dalam manajemen pemasaran, menyebabkan produk/ kebudayaan tidak dapat dipasarkan dengan baik (Widiastuti dkk., 2019).

Media jejaring sosial merupakan sarana yang efektif untuk mempromosikan budayabudaya nusantara, pengguna muda mendominasi pengguna internet di Indonesia, terutama media jejaring sosial. Hal ini menjadi kekuatan yang besar bagi peningkatan promosi kebudayaan nusantara. Untuk menarik minat pengguna muda diperlukan kreatifitas dan kemasan promosi yang menarik dengan tetap mengedepankan unsur budaya tradisional. Pencitraan budaya nusantara yang dikemas dengan teknologi dan penggunaan media jejaring sosial akan mengubah citra dan pandangan terhadap budaya itu sendiri.

Kegiatan PKM ini ditujukan untuk milenial Gen Z, dimana generasi ini memiliki karakteristik cakap dalam penggunaan media internet, khususnya media sosial. Media sosial sudah menjadi gaya hidup (life style) mereka, selain itu eksistensi mereka di dunia maya ini dikategorikan menjadi dua menurut Nukman di media online cnnindonesia.com dengan judul "Membaca Generasi Z Lewat Perilaku di Media Sosial" yakni creator dan conversationalist.

Creator adalah orang yang membuat konten tertentu di blog, situs web, atau pun akun YouTube, sedangkan conversationalist merupakan orang yang lebih senang menggunakan Facebook, Path, dan Twitter untuk berinteraksi. Nukman menilai bahwa Gen Z ada di kategori creator, karena banyak ruang yang bisa dimanfaatkan oleh mereka untuk berkreasi seperti Instagram. Adanya smartphone saat ini yang sudah sangat memadai juga untuk membuat foto, video 
dan editing. Tidak heran, Gen Z enggan untuk menjadi pegawai, cenderung menjadi entrepreneur atau self-employee.

Mengetahui hal ini, Gen Z memang kreatif menggunakan media sosial sebagai peluang usaha, melakukan personality brand dengan menggunggah segala macam bentuk aktivitas yang dilakukannya. Namun, masih belum melek media (literasi media) sebagai promosi pariwisata dan mengenalkan masing-masing kearifan lokal budaya yang dimiliki melalui akun instagram pribadi mereka. Dengan kata lain, minimnya tingkat kesadaran remaja milenial Gen Z untuk mengenalkan kearifan budaya lokal dan pariwisatanya.

Pada jurnal Pengabdian Kegiatan Masyarakat (PKM) sebelumnya dengan judul "Pelatihan Pemanfaatan Media Sosial Untuk Promosi Pariwisata dan Potensi Kearifan Lokal di Pantai Sayang Heulang Kab. Garut" disampaikan bahwa angka penetrasi media sosial terus bergerak naik menandakan luasnya penggunaan platform online di tengah masyarakat.

Kemudian, sesuai dengan sifat dasarnya media sosial memungkinkan semua orang berkreasi dan menyebarkan konten sendiri (user-generated content) sehingga pihak manapun sepanjang memiliki akun dan terkoneksi internet dapat aktif menjadi produser konten di berbagai platform jejaring sosial. Agar efektif digunakan sebagai saluran promosi pariwisata perlu adanya pembekalan mengenai strategi penggunaan dan penyiapan konten termasuk panduan etika bermedia sosial bagi stakeholders pariwisata.

Pembekalan ini diberikan pada masyarakat yang tinggal di Kebupaten Garut, yang mana mereka memiliki potensi kearifan lokal di Kawasan wisata Pantai Sayang Heulang Desa Mancagahar Kecamatan Pameungpeuk, Kabupaten Garut, Jawa Barat. Sedangkan, jurnal PKM ini berfokus pada memberikan pembekalan berupa pelatihan pada remaja milenial Gen Z tentang meningkatkan kesadaran diri terhadap upaya pelestarian budaya lokal, dan promosi budaya lokal di Kabupaten Kuningan, Jawa Barat yang belum dikenal dan diketahui oleh masayarakat luas melalui penggunaan media sosial Instagram secara optimal.

\section{Rumusan Masalah}

Kegiatan PKM ini merumuskan masalah sebagai berikut mengetahui bahwa Indonesia sedang menghadapi era revolusi industri 4.0, yang memengaruhi beragam aspek hingga lini. Salah satunya adalah aspek budaya, dimana jika tidak diupayakan untuk melakukan suatu perubahan atau peningkatan yang lebih baik maka kearifan lokal akan terkikis atau tergerus, sehingga akan memberikan efek yang cukup signifikan di beragam aspek yakni sosio-ekonomi, masyarakat lokal, dan sebagainya.

Tanggung jawab ini bukan hanya dibebankan kepada pemerintah, namun dari kita untuk kita dalam melestarikan kearifan lokal. Dalam upaya pelestariannya tersebut perlu dibantu untuk menumbuhkan kesadaran masyarakatnya khususnya remaja, sebab mereka adalah generasi muda yang dapat membantu melestarikan budaya lokal dengan mengenalkan budaya lokal yang mereka miliki, serta menumbuhkan bangga akan budaya lokalnya melalui media sosial Instagram sebagai mediumnya.

Oleh karenanya, Kabupaten Kuningan di Jawa Barat perlu diberikan sosialisasi literasi media berupa penggunaan media sosial Instagram untuk meningkatkan kesadaran remaja dalam melestarikan budaya lokalnya, seperti seni Wayang Golek merupakan seni peninggalan nenek moyang yang memiliki nilai-nilai (value) luhur serta penuh dengan falsafah kehidupan, kemudian Heman Ka Budak adalah kesenian Sunda yang diadakan helaran mingguan kebudayaan dan kesenian Kuningan, acara ini diselenggarakan oleh Dinas Pendidikan Kuningan yang berkolaborasi dengan seniman muda Kuningan. 
Acara ini ingin mengangkat kesenian asli budaya Sunda yang hampir terkikis dengan mengajak remaja untuk berpartisipasi tampil dan mengasah bakat atau potensi yang dimiliki. Dengan demikian dalam rumusan masalah yang akan diangkat adalah bagaimana penggunaan media sosial Instagram untuk meningkatkan kesadaran remaja akan pelestarian budaya, khususnya di Kabupaten Kuningan di Jawa Barat.

\section{Metode Kegiatan}

Usai disampaikan diatas mengenai rumusan masalah dalam kegiatan Pengabdian Kepada Masyarakat (PKM) ini, maka dalam metode kegiatan PKM dilakukan untuk meningkatkan softskill dan hardskill peserta yakni siswa-siswi SMA di Kabupaten Kuningan, Jawa Barat. Adapun kegiatan yang dilakukan di awal adalah dengan melakukan kordinasi topik, survei lokasi, rapat koordinasi dengan tim. Pada poin ini dilakukan oleh tim dengan pertemuan secara berkala, berupa brainstorming mengenai materi, serta metode penyampaian materi yang akan dilaksanakan saat pelaksanaan PKM.

Kemudian, dilakukan juga observasi di wilayah yang sudah ditentukan yakni Kuningan, Jawa Barat. Di poin ini juga, menyertakan mahasiswa untuk berpartisipasi dalam kegiatan PKM. Lalu poin berikutnya dilanjutkan dengan persiapan materi/teknik penyampaian dimana pada poin ke dua ini, dilakukan pemikiran yang matang terhadap materi yang akan disampaikannya, berupa topik utamanya, konten atau isi yang mau disampaikan yang disesuaikan dengan kebutuhan audience nya yakni siswa SMAN 1 Kuningan, Jawa Barat.

Selanjutnya, poin ke tiga pelaksanaan kegiatan. Pada poin ini mengikutsertakan mahasiswa dalam kegiatan pengabdian yang bertujuan agar mengimplementasikan ilmu yang sudah diberikan. Disini peran mahasiswa yang sudah diundang untuk ikut berpartisipasi akan membantu dalam pelaksanaan kegiatan dilakukan memberikan penyuluhan terlebih dahulu mengenai materi yang akan disampaikan nanti pada saat pelaksanaan kemudian diberitahukan juga mengenai metode penyampaiannya selama pelaksanaan berlangsung, kemudian instruktur memberikan peran yang harus dilakukan oleh mahasiswa saat dalam pelaksanaan penyuluhan dan pelatihan saat pelaksanaan kegiatan.

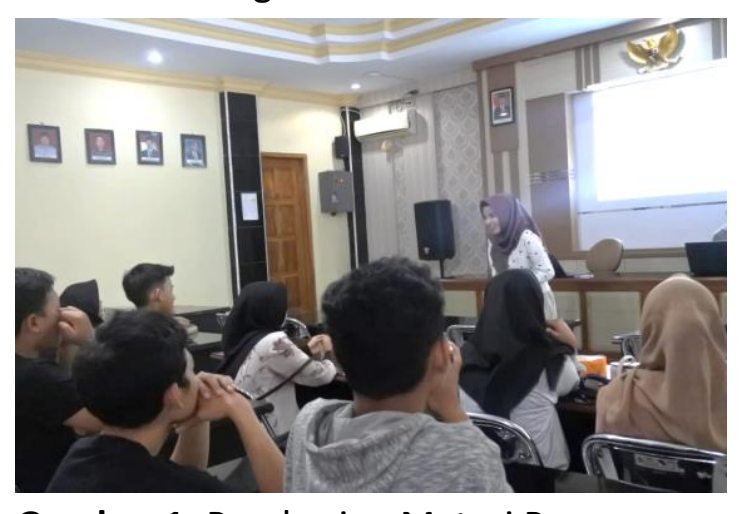

Gambar 1. Pemberian Materi Penggunaan Media Sosial Instagram (Sumber: Dokumentasi penulis)

\section{Pembahasan}

Tahap awal kegiatan PKM ini, dilakukan observasi dan survei awal di daerah kegiatan yakni di Kabupaten Kuningan. Pada tahap awal ini, pertemuan dengan Bapak Dodon Sugiarto dari Dinas Pendidikan dan Kebudayaan Kabupaten Kuningan, Jawa Barat juga selaku penggagas kegiatan Heman Ka Budak, Kepala Sie Pendidikan dan Kebudayaan (Slamet Riyadi), Staf Area (Barnas Susanto, Ehan Rohandi), kemudian Seniman Lokal (Abah Deden Swaloka).

Dalam pertemuan ini dihasilkan beberapa hal diantaranya, kesepakatan untuk mengadakan kegiatan pendampingan kepada para siswa SMA dalam penggunaan media sosial Instagram sebagai pelestarian budaya. Sebelumnya telah dilakukan FGD (Focus Group Discussion) dengan Kabid Pendidikan dan Kebudayaan, Kepala Sie Pendidikan dan Kebudayaan, Staf Area, Seniman Lokal yang berjumlah sembilan orang, hasilnya menujukan bahwa masyarakat harus selalu diingatkan akan budaya lokal Kuningan, Jawa Barat yang 
dimiliki melalui pagelaran seni budaya Heman Ka Budak yang diselenggarakan setiap minggu.

Acara ini bertujuan untuk meningkatkan kesadaran masyarakat dengan menampilkan seni budaya lokal melalui tarian-tarian yang selama ini hampir ditinggalkan oleh masyarakatnya. Tidak hanya itu, memberikan kesempatan bagi generasi muda untuk menampilkan talenta seni yang dimilikinya, serta meningkatkan keberanian diri melalui tarian tersebut.

Mayoritas masyarakat memfungsikan teknologi media sosial mereka untuk hiburan saja, tanpa menggunakannya sebagai fungsi informasi mengenai kegiatan Heman Ka Budak, inilah sebagai salah satu hambatan atau kendala yang dihadapi yakni literasi media sosial yang masih kurang. Tidak hanya itu saja, hasil dari FGD menyatakan peserta juga mengakui adanya kesulitan dalam memberdayakan kegiatan Heman Ka Budak untuk meraih donasi meski penggunaan media baru sebagai strategi promosi memperkenalkan seni lokal telah dilakukan, belum mampu menarik perhatian para donatur.

Dengan kata lain, kegiatan promosi untuk mengenalkan budaya lokal melalui acara Heman Ka Budak masih kurang. Oleh sebab itu, mengetahui bahwa banyak yang menggunakan media sosial Instagram adalah Gen Z maka untuk meningkatkan kesadaran remaja Generasi $Z$ dalam kegiatan pengabdian ini adalah memberikan literasi media sosial Instagram untuk promosi budaya lokal yang dimiliki Kuningan, Jawa Barat melalui akun Instagram pribadinya.

Media sosial merupakan media yang paling sering digunakan oleh generasi milenial dalam kehidupan sehari-hari. Berdasarkan data yang di release oleh Hootsuite, menangani profil media sosial yakni audience profile, pada Januari 2019, terlihat bahwa audiens terbesar pengguan media sosial adalah generasi muda dalam rentang 18-34 tahun, yang mencapai $37 \%$.
Media sosial digunakan sebagai alat penyebaran informasi, dimana Indonesia memiliki banyak suku, budaya, destinasi wisata alam yang sangat indah. Di zaman era yang serba mudah saat ini, masyarakat Indonesia, khususnya generasi milenial dan Gen Z, memiliki peluang untuk memperkenalkan daerahnya, baik dalam skala nasional maupun internasional. Remaja menggunakan media sosial, khususnya Instagram adalah untuk mereperesentasikan diri, sebagai bagian dari self-image dan self-identity.

Kegiatan pengabdian dilakukan pada Minggu, 30 Juni 2019 di SMAN 1 Kuningan, Jawa Barat. Materi disampaikan dalam bentuk pelatihan dan sharing session dengan siswa/siswi SMAN kelas 12 yang aktif melakukan kegiatan seni tari budaya lokal Kuningan dengan alat bantu powerpoint yang disajikan melalui LCD. Pada pemaparan materi ini, diarahkan pada pengenalan dan pemahaman peserta tentang media sosial dan bagaimana memanfaatkannya untuk promosi budaya lokal dengan menekankan pada konten, angle foto yang disajikan di Instagram.

Selama kegiatan berlangsung, respon peserta ditunjukan dengan antusiasme mereka baik secara verbal dan non-verbal komunikasi dimana peserta memberikan respon positif dengan melontarkan berbagai pertanyaan di sela-sela pemaparan materi. Terlihat bahwa banyak hal yang peserta belum ketahui bahwa dengan membagikan kegiatan mereka melalui akun Instagram pribadi yang selama ini dilakukan adalah salah satu bentuk upaya mereka dalam mengenalkan budaya lokal Kuningan, Jawa Barat meskipun belum optimal. Adanya kegiatan pengabdian ini diberikan strategi komunikasi yang bisa dilakukan oleh peserta terkait dengan pengemasan pesan melalui konten-konten yang menarik.

\section{Kesimpulan \\ Kegiatan pengabdian kepada masyarakat yang berupa pelatihan}


penggunaan media sosial Instagram untuk meningkatkan kesadaran remaja akan pelestarian budaya lokal di Kabupaten Kuningan, Jawa Barat dapat disimpulkan bahwa peserta yang sebelumnya belum memahami mengenai pemanfaatan media sosial Instagram sebagai pelestarian budaya lokal Kabupaten Kuningan usai mengikuti pelatihan. Berikutnya, peserta yang sebelumnya belum memahami mengenai peran pentingnya generasi muda untuk berpartisipasi dalam kegiatan promosi budaya Kuningan, setelah mengikuti pelatihan ini.

Terakhir, peserta yang sebelumnya tidak mempunyai keterampilan dalam membuat promosi budaya yang menarik dan efektif melalui media sosial Instagram sebagai mediumnya, setelah mengikuti pelatihan muncul ide-ide kreatifitas dan lebih terampil dalam membuat konten-konten di Instagramnya. Dengan kata lain, pentingnya kearifan lokal dengan memanfaatkan kemajuan teknologi dalam hal ini Instagram, merupakan upaya pembentukkan identitas bangsa Indonesia yang mana saat ini concern utama agar tidak terkikis oleh budaya global yang masuk seiring berkembanganya kemajuan teknologi.

Sebab, jika tidak diupayakan dengan menumbuhkan kesadaran pada generasi muda maka arus golbalisasi dan teknologi informasi yang sangat cepat dapat memberikan pengaruh besar terhadap cara pandang, budaya, dan gaya hidup di kalangan generasi milenial yang sudah masuk pada Gen Z.

\section{Ucapan Terima Kasih}

Terima kasih kepada Lembaga Pengabdian Masyarakat Universitas Bakrie yang telah mendanai dan memfasilitasi dalam pelaksanaan kegiatan PKM ini, lalu terima kasih juga pada sekolah SMAN 1 Kuningan, Jawa Barat yang telah berpartisipasi dalam kegiatan pelatihan mengenai penggunaan media sosial Instagram sebagai media untuk promosi budaya lokal Kabupaten Kuningan, Jawa Barat. Terima kasih juga pada masyarakat lokal Kabupaten Kuningan, Jawa Barat yang telah memperkenalkan berupa tarian, nyanyian budaya Kuningan melalui Heman Ka Budak di Car Free Day (CFD) Jawa Barat.

\section{Daftar Pustaka}

Ananda, Dwi Rizqa. 2018. Presiden Jokowi dan Menristekdikti Mohamad Nasir Tekankan Pentingnya Investasi di Bidang Sumber Daya Manusia [Internet]. [Diakses pada 25 Juli 2018]. Tersedia pada: https://www.ristek dikti.go.id/siaran-pers/presiden-jokowidan-menris tekdikti-mohamad-nasirtekankan-penti ngnya-investasi-dibidang-sumber-daya-ma-usia/2/

Andriani, Dewi. 2018. Generasi Milenial Perlu Jaga Kearifan Lokal [Internet]. [Diakses pada 15 Desember 2018]. Tersedia pada: https://kabar24.bisnis. com/read/20181201/15/865322/genera si-milenial-perlu-jaga-kearifan-lokal

Atiko, Gito., Sudrajat, Ratih Hasanah., Nasionalita, Kharisma. 2016. Analisis Strategi Promosi Pariwisata Melalui Media Sosial Oleh Kementerian Pariwisata RI. Jurnal Sosioteknologi, 15(3): 378-389.

Gumilar, Gumgum., Adiprasetio, Justito., Maharani, Nunik. 2017. Literasi Media: Cerdas Menggunakan Media Sosial Dalam Menanggulangi Berita Palsu (HOAX) Oleh Siswa SMA. Jurnal Pengabdian Kepada Masyarakat Universitas Padjajaran, 1(1): 35-40.

Gumilar, Gumgum. 2015. Pemanfaatan Instagram Sebagai Sarana Promosi Oleh Pengelola Industri Kreatif Fashion Di Kota Bandung. Jurnal IImu Politik dan Komunikasi, V(2): 77-84.

Hilmi, M.A. Al,\& Fajar, G. 2010. Pemanfaatan Game Mobile Pada Platform Android Berbasis Unity Game Engine Untuk Melestarikan Bahasa Daerah Cirebon di Kalangan Genereasi Muda. Jurnal Arus Elektro Indonesia, 2(3): 25-29. 
JPNN.com. 2018. Generasi Milenial Diajak Menjadi Pelopor Perdamaian [Internet]. [Diakses pada 30 November 2018]. Tersedia pada: http://www.jpnn.com/ news/generasi-milenial-diajak-menjadipelopor-perdamaian

Machruf, B., Hairunnisa, Wibowo, S.E. 2018. Peran Media Sosial Instagram Dalam Menarik Minat Berkunjung Mahasiswa Ilmu Komunikasi Universitas Mulawarman Di Wisata Ladang Budaya Tenggarong. Jurnal IImu Komunikasi Universitas Mulawarman, 7(1).

Putranto, W. A.,\& Sari, I.N. 2018. Pelestarian Warisan Budaya Di Local Studies Center Dengan Pemanfaatan Media Sosial. Diplomatika: Jurnal Kearsipan Terapan, 1(2): 71-81.

Saputra, Sandi Jaya., Adiprasetio, Justito., Kusmayadi, Ika Merdekawati. 2018. Pentingnya Literasi Media. Jurnal Pengabdian Kepada Masyarakat Universitas Padjajaran, (2)3.

Satria. 2018. Minimalkan Pengaruh Budaya Asing, PKKH Gelar Sarasehan Budaya dan Pancasila [Internet]. [Diakses pada 4 Desember 2018]. Terdapat pada: https://www.ugm.ac.id/id/newsPdf/238 1-minimalkan.pengaruh.budaya.asing. pkkh.gelar.sarasehan.budaya.dan.panca sila

Setyaningrum, M. H. H. 2018. Influencer Instagram Menjadi Penggerak Yang Menceriminkan Nilai Gotong Royong di Palu Donggala. Madiun: Universitas Katolik Widya Mandala Madiun
Sj., Nuyah Asri. 2018. Pelatihan Pemanfaatan Media Sosial untuk Promosi Pariwisata dan Potensi Kearifan Lokal Di Pantai Sayang Heulang Kab. Garut. Jurnal Pengabdian Kepada Masyarakat Universitas Padjajaran, 2(2).

Sofyan, Eko Hendrawan (Ed). 2012. 39 Kesenian Jabar Punah [Internet]. [Diakses pada 17 November 2019]. Terdapat pada: https://nasional.kompas .com/read/2012/10/05/06165929/39.K esenian.Jabar.Punah

Suasih, E. 2018. The Branding Of Surabaya Through Its Local Food In@ Kulinersby Instagram Account: A Critical Visual Analysis [Disertasi]. Surabaya: Universitas Airlangga.

Widayanti, Riya. 2015. Pemanfaatan Media Sosial Untuk Penyebaran Informasi Kegiatan Sekolah Menengah Kejuruan Pasundan Tangerang. Jurnal Abdimas Universitas Esa Unggul, 1(2).

Widiastuti, T., Mihardja, E., Agustini, P. 2019. Women's Participation on Tourism Villages' Management in The Dieng Pandawa Tourism Awareness Group. ASEAN Journal of Community Engagement, 3(1): 122-138. 